\title{
CONVENIÊNCIA DA CIÊNCIA NA POLÍTICA BRASILEIRA DE ALFABETIZAÇÃO
}

\author{
Convenience of science in Brazilian literacy policy
}

Wagner Rodrigues SILVA

Universidade Federal do Tocantins

Bolsista de Produtividade do CNPq

wagnersilva@uft.edu.br

https://orcid.org/0000-0002-3994-1225

Os resultados insatisfatórios demonstrados por crianças dos anos iniciais do Ensino Fundamental, em práticas de leitura e escrita, revelam que o processo de alfabetização corresponde a um imenso desafio para as escolas brasileiras (BRASIL, 2017). Quando tais resultados são conhecidos pela população, que compartilha de alguma indignação, gestores públicos recém-empossados podem se utilizar do contexto escolar adverso como um trunfo para justificar uma política educacional em contraposição. Tal atitude pode ser ameaçadora se tratando de gestores com pretensão de reformas educacionais alinhadas a preceitos típicos do fascismo ("Ur-Fascismo" ou "Fascismo Eterno"), no sentido empregado por Eco (2017) ${ }^{1}$.

No Brasil, a necessidade de uma política de alfabetização eficaz se fortalece diante da quinta meta do Plano Nacional de Educação, vigente entre os anos de 2014 a 2024. Assim, dentre as vinte metas a serem alcançadas na referida década, objetiva-se "alfabetizar todas as crianças, no máximo, até o final do $3^{\circ}$ (terceiro) ano do ensino fundamental" (BRASIL, 2014, p. 26). De alguma forma, o tamanho do desafio da política de alfabetização desejada pode ser delineado a partir do último diagnóstico da proficiência em leitura mensurado pela Avaliação Nacional da Alfabetização (ANA), aplicada a

\footnotetext{
${ }^{1}$ Eco (2017, p. 23-24) lista quatorze características do fascismo, dentre as quais destaco: "culto da tradição"; "rejeição do modernismo"; "culto da ação pela ação"; "obsessão da conspiração"; "elitismo"; "machismo"; "populismo qualitativo". Para os fascistas, ainda nos termos do autor: "O irracionalismo depende também do culto da ação pela ação. A ação é bela em si, e portanto tem de ser realizada antes de e sem qualquer reflexão. Pensar é uma forma de castração. Por isso a cultura é suspeita na medida em que se identifica com comportamentos críticos. [...] a suspeita em relação ao mundo intelectual tem sido sempre um sintoma de Ur-Fascismo. Os intelectuais fascistas oficiais empenharam-se principalmente em acusar a cultura moderna e a intelligentzia liberal de ter abandonado os valores tradicionais" (grifos do original).
} 
crianças do $3^{\circ}$ ano do Ensino Fundamental, em escolas públicas brasileiras ${ }^{2}$. O diagnóstico da proficiência em leitura revelou que 54,73\% dos concluintes do então denominado Ciclo de Alfabetização se encontram nos dois primeiros níveis de um total de quatro, sendo os primeiros caracterizados como insuficientes (BRASIL, 2017).

Este artigo traz uma crítica à atual política de alfabetização, em implementação pelo governo federal brasileiro, composto por um grupo de extrema direita posto no poder após um pleito dito democrático. Descrita numa espécie de caderno oficial, a Política Nacional de Alfabetização (PNA) foi instituída a partir de diretrizes estabelecidas no decreto $\mathrm{N}^{\circ}$ 9.765/2019, de 11 de abril de 2019 (BRASIL, 2019). Nessa política, a "instrução fônica sistemática", fundamentada na denominada Ciência Cognitiva da Leitura, compreendida como um "campo interdisciplinar que abrange as diferentes disciplinas que estudam a mente e sua relação com o cérebro" (BRASIL, 2019, p. 20), é assumida, desdobrando-se em parâmetros metodológicos a serem utilizados no processo de alfabetização.

A PNA se configura como uma medida autoritária por cercear outras escolhas por parte das alfabetizadoras, ignorar os saberes construídos por essas professoras com base em evidências da própria prática profissional e, inclusive, outras perspectivas ou propostas teórico-metodológicas ancoradas em pesquisas orientadas por outro paradigma investigativo, legítimo e diferente do que sustenta estudos experimentais ou das neurociências. As relevantes contribuições dos estudos dos letramentos, produzidas dentro e fora do Brasil (COOK-GUMPERZ, 2002; KLEIMAN, 1995; SOARES, 2003), por exemplo, foram ignoradas em detrimento da proposição de uma compreensão confusa do que se denomina de literacia $^{3}$, palavra pertencente apenas ao português europeu, registrada no Vocabulário Ortográfico Português (Vop) ${ }^{4}$.

É inquestionável a relevância da abordagem fônica para que, inicialmente, as crianças compreendam distintas relações entre fonemas e grafemas, bem como outros mecanismos fonológicos característicos do sistema alfabético-ortográfico da língua portuguesa, a exemplo de composições e tonicidades silábicas e, até mesmo, de pausas

\footnotetext{
${ }^{2}$ Participaram da avaliação alunos de "escolas públicas com pelo menos 10 estudantes matriculados no $3^{\circ}$ ano do Ensino Fundamental em 2016" (BRASIL, 2017, s/p).

${ }^{3}$ Um estudo aprofundado sobre a concepção de literacia na PNA é apresentado por Silva (2020).

${ }^{4}$ Fonte: <http://www.portaldalinguaportuguesa.org/index.php?action=lemma\&lemma=84744 >. Acesso em: 29 ago. 2020.
} 
marcadas por sinais de pontuação. Mas a alfabetização, compreendida como um processo de conscientização dos alunos sobre o funcionamento da escrita do português, possibilitando-lhes ler e escrever, torna-se mais produtiva quando desenvolvida em contextos de letramentos planejados, ou seja, envolvida em diversificadas práticas de leitura e escrita mediadas por alfabetizadoras.

Assim como revelam alguns estudos reunidos em Cook-Gumperz (1991), pesquisas científicas mostram que crianças de lares com significativa exposição a práticas de leitura e escrita tendem a demonstrar um desempenho superior, no processo de escolarização, em relação a crianças menos privilegiadas. Esses estudos demonstram a relevância da abordagem dos letramentos não apenas durante a alfabetização, com propósito de contextualizar o trabalho sobre o sistema, mas ainda no período anterior e posterior ao referido processo.

Na PNA, tem-se uma concepção de alfabetização restrita, desprezando o caráter social da alfabetização, atento a demandas e culturas diversas levadas para escolas pelos alunos. Esse fato se torna ainda mais evidente em uma das ações de implementação da política,trata-se do curso on-line de "Formação Continuada em Práticas de Alfabetização", “Tempo de Aprender”, disponível na plataforma virtual do Ministério da Educação 5 . Marcado por atividades pedagógicas repetitivas, o curso parece ignorar a autonomia das alfabetizadoras e menosprezar o trabalho com textos de gêneros diversos. Na mente do cursista experiente, ativa a lembrança das atividades de antigas cartilhas. Sobre o papel dos textos numa pedagogia influenciada pelo fascismo, Eco (2017, p. 28) afirma que "Todos os textos escolares nazis ou fascistas assentavam num léxico pobre e numa sintaxe elementar, com o fim de limitar os instrumentos para o raciocínio complexo e crítico”.

Para sustentar os pressupostos teóricos assumidos na PNA, afirma-se, inúmeras vezes, que a política foi elaborada para promover "a alfabetização baseada em evidências científica", conforme exposto no Art. $1^{\text {o }}$ do Decreto No 9.765, de 11 de Abril de 2019, como se as políticas oficiais anteriores não usufruíssem de semelhante legitimidade. Há pessoas comuns e, inclusive, profissionais da educação com formação precária, por exemplo, que desconhecem a complexidade subjacente a práticas alfabetizadoras. Certamente, acreditam que o processo de alfabetização se limita à reprodução ou, quando

\footnotetext{
${ }^{5}$ Fonte: <http://avamec.mec.gov.br/\#/instituicao/sealf/curso/5401/visualizar>. Acesso em: 29 ago. 2020.
} 
muito, ao desenvolvimento de estratégias garantidoras da memorização de letras e sílabas pelos alunos, informadas por saberes da tradição escolar ou, até mesmo, de um suposto ato criativo. É pertinente o uso do discurso em torno das evidências científicas para se contrapor a crenças desse tipo, mas é inadmissível ignorar, como interlocutores, pesquisadores responsáveis pela produção e proposição de outras perspectivas teóricometodológicas para a alfabetização. As ciências são (ou deveriam ser) produzidas na diversidade, no diálogo respeitoso entre especialistas com formações distintas.

Mas quais são as evidências científicas mencionadas na PNA? Além de literaturas científicas citadas, são realçados os relatórios "Alfabetização Infantil: Novos Caminhos" (2003), encomendado pela Comissão de Educação e Cultura da Câmara dos Deputados, e “Aprendizagem Infantil: uma Abordagem da Neurociência, Economia e Psicologia Cognitiva" (2011), elaborado pela Academia Brasileira de Ciências. Há membros semelhantes nos grupos de trabalho responsáveis pela produção dos referidos relatórios e da PNA, o que justifica o alinhamento teórico-propositivo entre os três documentos.

Conforme perceptível, a política focalizada foi gestada desde os primeiros anos deste século e, certamente, não obteve espaço nas gestões públicas lideradas pela esquerda partidária. É de se estranhar o uso da ciência como argumento para sustentar uma política educacional, por parte de um governo conhecido por ignorar orientações científicas, a exemplo da postura negacionista do próprio presidente da república, no combate à Pandemia da COVID-19 $9^{6}$ O discurso de legitimação subjacente à expressão evidências científicas foi questionado em estudos reunidos por Thomas e Pring (2007). Os relatórios com sínteses teóricas podem contribuir para esclarecer ou enfrentar algum problema, mas os critérios utilizados para selecionar as pesquisas reunidas são passíveis de questionamentos, pois podem esconder interesses particulares ou institucionais. Sobre a PNA, faz-se necessário questionar o desprezo das pesquisas nacionais e internacionais de

\footnotetext{
${ }^{6}$ Uma evidência do desprezo do presidente brasileiro por recomendações científicas é o pronunciamento realizado em rede nacional de rádio e televisão, no dia 24 de maio de 2020 . O excerto reproduzido revela ainda o menosprezo do presidente pelas vidas dos brasileiros, especialmente pelos idosos. Durante a escrita deste artigo, o quantitativo de pessoas vitimadas pela COVID-19, no Brasil, já ultrapassava 130 mil, alcançando pessoas de diferentes faixas etárias. Segue o excerto do pronunciamento presidencial: "O que se passa no mundo tem mostrado que o grupo de risco é o das pessoas acima dos 60 anos. Então, por que fechar escolas? Raros são os casos fatais de pessoas sãs, com menos de 40 anos de idade. [...] No meu caso particular, pelo meu histórico de atleta, caso fosse contaminado pelo vírus, não precisaria me preocupar, nada sentiria ou seria, quando muito, acometido de uma gripezinha ou resfriadinho". Fonte: $<$ https://noticias.uol.com.br/politica/ultimas-noticias/2020/03/24/leia-o-pronunciamento-do-presidente-jairbolsonaro-na-integra.htm>. Acesso em: 29 ago. 2020.
} 
base antropológica e situadas nos estudos dos letramentos.

O envolvimento da alfabetização em disputas ideológicas fora registrado pela História, cuja legitimidade, assim como outras disciplinas das humanidades, tem sido questionada pelo entorno presidencial. No contexto britânico, Cook-Gumperz (1991, p.33) afirma que "houve um tempo em que muitas pessoas influentes viam a alfabetização como um poder muito perigoso para a maioria das classes trabalhadoras". Temiam que a condição de alfabetizados pudesse oportunizar perspectivas futuras diferenciadas aos trabalhadores, reduzindo o quantitativo de mão de obra barata e subserviente. A autora comenta ainda que a "alfabetização popular [...] foi associada com causas políticas radicais" (COOK-GUMPERZ, 1991, p. 37). No território brasileiro, por volta dos anos 1960, o interesse político pelo movimento de alfabetização de adultos liderado pelo educador Paulo Freire se sustentava, inicialmente, pela ampliação do número de eleitores, mas passou a ser visto como ameaça às oligarquias fragilizadas quando se descobriu que a abordagem freiriana estava comprometida com o empoderamento dos trabalhadores ${ }^{7}$.Tratava-se de uma concepção de alfabetização bastante próxima do que, mais recentemente, foi denominado letramentos, mais especificamente em abordagens críticas (SILVA, 2019) ${ }^{8}$.

As escolhas teóricas realizadas na composição da PNA não foram aleatórias, assim como não foram as realizadas para a produção de políticas educativas em governos anteriores. Na política problematizada, dos alunos, restringe-se uma formação diversificada e conscientizadora; das alfabetizadoras, deseja-se uma operacionalização obediente; e dos especialistas desalinhados, o silêncio. Como fruto da insubordinação,os diferentes atores sociais podem responder em contra movimentos de resistência, a

\footnotetext{
${ }^{7}$ Conforme Francisco C. Weffort (2017, p. 28-29), em prefácio do livro "Educação como prática de liberdade", de Paulo Freire, "Os grupos de direita nunca fizeram segredo de sua má vontade em relação a qualquer tentativa de ampliação do eleitorado. [...] Daí sua manifesta oposição ao projeto de extensão do direito de voto aos analfabetos. Se a participação das massas alfabetizadas já alterava substancialmente o quadro das relações de poder, o que ocorreria se fosse permitida a participação do conjunto das classes populares? Para os grupos da direita, isso parecia significar o fim da democracia. Em verdade, poderia significar o começo de uma verdadeira democracia para o povo e o fim da história política de muitos dos setores privilegiados".

${ }^{8}$ Em biografia dedicada a Paulo Freire, Sérgio Haddad (2019, p. 223), afirma que, "Em seu programa de governo para a Educação, [Jair Bolsonaro] defendeu expurgar o pensamento do educador das escolas. Setores conservadores da sociedade brasileiras, ancorados no alcance das redes sociais, se empenharam novamente em desqualificar e banir a filosofia educacional de Paulo Freire. Carlos Bolsonaro, filho do candidato, vinha atacando o educador no Twitter desde 2016".
} 
exemplo do que possibilita a abordagem da Educação Científica assumida neste artigo (SILVA, 2019).

Nesse sentido, destaca-se, finalmente, que a produção desta crítica foi orientada por pressupostos teóricos da Educação Científica, caracterizada como uma abordagem investigativa da Linguística Aplicada, com futuro promissor para se sustentar como uma área do conhecimento no referido campo de pesquisa (SILVA, 2020). Influenciada por estudos dos letramentos, essa abordagem possibilita compreender como os usos das ciências (ou, inclusive, a ausência delas), em textos escritos, orais ou multimodais, podem influenciar o cotidiano das pessoas, especialmente em situações sustentadas por interesses ou forças em disputas.

\section{REFERÊNCIAS}

BRASIL. Planejando a próxima década: conhecendo as 20 metas do Plano Nacional de Educação. Brasília: Ministério da Educação, 2015. Fonte: $<$ http://pne.mec.gov.br/images/pdf/pne_conhecendo_20_metas.pdf $>$. Acesso em: 29 ago. 2020.

BRASIL. Sistema Nacional de Avaliação da Educação Básica: Avaliação Nacional da Alfabetização Edição 2016. Brasília: Instituto Nacional de Estudos e Pesquisas Educacionais Anísio Teixeira, 2017. Fonte: <http://portal.mec.gov.br/docman/outubro2017-pdf/75181-resultados-ana-2016-pdf/file>. Acesso em: 29 ago. 2020.

BRASIL. Política Nacional de Alfabetização. Brasília: Ministério da Educação, 2019. Fonte: <http://portal.mec.gov.br/images/banners/caderno_pna_final.pdf>. Acesso em: 29 ago. 2020.

COOK-GUMPERZ, J. (Org.). A construção social da alfabetização. Porto Alegre: Artmed Editora, 1991.

ECO, U. Como reconhecer o fascismo e da diferença entre migrações e emigrações. Lisboa: Relógio D'Água Editores, 2017.

HADDAD, S. O educador: um perfil de Paulo Freire. São Paulo: Todavia, 2019.

KLEIMAN, A. Os significados do letramento: uma nova perspectiva sobre a prática social da escrita. Campinas: Mercado de Letras, 1995.

SILVA, W. R. Polêmica da alfabetização no Brasil de Paulo Freire. Trabalhos em Linguística Aplicada. Campinas: Unicamp, v.58, n.1, p.219-240, 2019. 
SILVA, W. R. Letramento ou literacia? Ameaças da cientificidade. In: SILVA, W. R. Contribuições sociais da Linguística Aplicada: uma homenagem a Inês Signorini. Campinas: Pontes, 2020, no prelo.

SOARES, M. Alfabetização e letramento. São Paulo: Contexto, 2003.

THOMAS, G.; PRING, R. (Org.). Educação baseada em evidências: a utilização dos achados científicos para a qualificação da prática pedagógica. Porto Alegre: Artmed, 2007.

WEFFORT, F. C. Educação e política: reflexões sociológicas sobre uma pedagogia da liberdade. In: FREIRE, P. Educação como prática da liberdade. São Paulo/Rio de Janeiro: Paz \& Terra, 2017, p. 8-39. 